\title{
Decrease in radiation therapy rates in patients with stage I seminoma: a population-based study
}

\author{
Shi Jia ${ }^{1}$, Jingping Qiu $^{2}$ \\ ${ }^{1} 7$ th General Surgery Unit, Shengjing Hospital of China Medical University, Shenyang, China; ${ }^{2}$ Department of Radiation Oncology, the First \\ Hospital of China Medical University, Shenyang, China \\ Contributions: (I) Conception and design: J Qiu; (II) Administrative support: All authors; (III) Provision of study materials or patients: All authors; (IV) \\ Collection and assembly of data: J Qiu; (V) Data analysis and interpretation: All authors; (VI) Manuscript writing: All authors; (VII) Final approval of \\ manuscript: All authors. \\ Correspondence to: Jingping Qiu, MD, PhD. Department of Radiation oncology, the First Hospital of China Medical University, 155 Nanjing North \\ Street, Heping District, Shenyang 110001, China. Email: qiujingping@outlook.com.
}

Background: Radiotherapy has long been considered the standard adjuvant treatment after radical orchidectomy for stage I seminoma. However, active surveillance and carboplatin chemotherapy have recently become alternative strategies. Despite this, the transition in management regimens is not yet fully recognized. Thus, this study aimed to analyze the 40-year trend in radiotherapy for patients with stage I seminoma in the United States.

Methods: We identified 21,976 men in the Surveillance, Epidemiology, and End Results (SEER) database who were registered in 18 centers and who had a diagnosis of localized testis seminoma between 1975 and 2015. Patients of unknown age or whose tumors were not malignant were excluded. We investigated the rate of radiotherapy, chemotherapy and surveillance by year of diagnosis, clarified the characteristics related to the decline in radiotherapy rate, and analyzed patient survival by year of diagnosis.

Results: From 1975 to 2015, 52.9\% (11,622/21,976) patients with stage I seminoma received external radiotherapy. The rate of radiotherapy, however, gradually decreased to $46.7 \%$ (189/405) in 2008, $18.6 \%$ (70/376) in 2012, and 5.3\% (19/359) in 2015. Patients aged under 34 years and married patients were more likely to avoid radiotherapy in the $21^{\text {st }}$ century. Compared with the 1975-1999 time period, patient overall survival (OS) decreased significantly in 2000-2007. However, OS during 2008-2015 was not statistically different than that during the 1975-1999 time period.

Conclusions: The role of radiotherapy in patients with stage I seminoma has fundamentally changed in the past 40 years and is no longer an essential treatment in the real-world management of this patient group.

Keywords: Seminoma; trends; beam radiation; treatment

Submitted Jul 17, 2020. Accepted for publication Oct 30, 2020.

doi: $10.21037 /$ tcr-20-2545

View this article at: http://dx.doi.org/10.21037/tcr-20-2545

\section{Introduction}

Testicular germ cell tumors comprise only 1-2\% of all cancers in the general population, but account for approximately $98 \%$ of all testicular malignancies (1). Seminomas are more common than non-seminomas among men (2). The majority of seminomas, which means "tumor confined to the testis", are pathological stage T1 (3).
Paraaortic (PA) and pelvic lymph nodes are at the greatest risk of metastases after radical orchidectomy. Adjuvant radiotherapy to these sites decreases the risk of metastasis, and therefore, became the standard adjuvant treatment for stage I seminoma for decades. Almost $100 \%$ of the cancerspecific survival (CSS) of patients with CS1 testicular seminoma has been achieved with a multidisciplinary management $(4,5)$. 
Postoperative radiotherapy has been considered the standard adjuvant treatment for localized testicular seminoma in the last century. However, given that seminoma is a highly curable disease, efforts have been made to minimize radiotherapy-induced damage by reducing the target field size and decreasing the prescription dose. In 1999, Fossa recommended that adjuvant radiotherapy be confined to the PA lymph nodes in order to replace PA and ipsilateral iliac lymph node irradiation [dogleg (DL) field] and indicated that this would lead to the same rate of recurrence rate, but lower toxicity (6). In 2005, Jones et al. suggested a dose reduction from 30 to $20 \mathrm{~Gy}$ in 10 fractions in order to help patients avoid delays in returning to work without more failure in relapse rates (7). Further, two other studies revealed that carboplatin chemotherapy and active surveillance can provide disease control equivalent to that of radiotherapy, and thus, could be used as alternative treatment strategies. Oliver et al. reported a non-inferiority of carboplatin to radiotherapy in the context of relapse-free survival rates for stage I seminoma (8). Meanwhile, based on the fact that salvage radiotherapy and chemotherapy have a low relapse-free rate in stage I testicular seminoma, Choo et al. showed that active surveillance is a safe alternative to these treatments (9). Despite the evidence that radiotherapy, carboplatin, and surveillance can lead to excellent outcomes in stage I seminoma, expert opinions and guidelines still differ (10-13).

Reported data from previous studies have the ability to drive small changes in the postoperative treatment strategy used by practitioners; however, the extent to which realworld clinical practices endorse such treatment strategies is not fully understood. Thus, this study aimed to analyze the 40-year trend in external radiotherapy for patients with testicular seminoma in the United States (US) using the Surveillance, Epidemiology and End Results (SEER) database. We present the following article in accordance with the STROBE reporting checklist (available at http:// dx.doi.org/10.21037/tcr-20-2545).

\section{Methods}

With permission from the National Cancer Institute, we used data from the SEER database, which collects information from population-based cancer registries covering approximately $34.6 \%$ of the US population. The data contain patient demographics, primary tumor site, stage at diagnosis, treatment, and follow-up. The study protocol was deemed to be exempt from institutional review board of our hospital due to its retrospective nature and the need for informed consent was waived. The study was conducted in accordance with the Declaration of Helsinki (as revised in 2013).

We identified 21,994 patients from the incidence database of SEER 18 Regs Custom Data (with additional treatment fields), which was submitted in November 2018 (1975-2016 varying) using the National Cancer Institute SEER*Stat software (Surveillance Research Program, version 8.3.6). The inclusion criteria were: (I) site recode of ICD-O-3/WHO 2008 is testis, (II) ICD-O-3 Hist/behav, malignant is $9061 / 3$ : seminoma, NOS, and (III) stage is localized. Exclusion criteria were (I) not malignant behavior, (II) unknown age, and (III) cases not in the research database. Stage was defined by summary/historic SEER historic stage A [1973-2015], which is derived from the Collaborative Stage (CS) 2004-2015 and Extent of Disease (EOD) 1973-2003. It is a simplified version of stage: in situ, localized, regional, distant, and unknown. Localized stage was described as an invasive neoplasm confined entirely to the organ of origin. For all the different EOD schemes that have been used over time, the SEER Program strives to make all stage variables consistent.

Information on the year of diagnosis, patient age at diagnosis, marital status, race, laterality, and region were obtained from the database. Treatment of surgery was adapted from the variable of "Reason no cancer directed surgery". Data on radiation and chemotherapy treatment were also included in the database. The treatment of surveillance was calculated from the usage of radiotherapy and chemotherapy; if neither was performed, surveillance was considered. Overall survival (OS) and cause-specific death were analyzed in months.

\section{Statistical analysis}

Percentages of patients receiving radiation between groups were compared using chi-square test. The 5 - and 10 -year cause specific survival rates and OS rates were estimated by Kaplan-Meier analyses, and compared by Log-Rank test. Statistical tests were 2-tailed, and the probability of a type I error was set at $\mathrm{P}<0.05$. All analyses were performed using IBM SPSS Statistics (version R24.0.0.0, IBM Corp., Armonk, NY, USA). Survival curves in Figure 1 was exported from SPSS statistics and the graphs were created in GraphPad Prism (version 8.0.0, GraphPad Software, Inc.). 
A

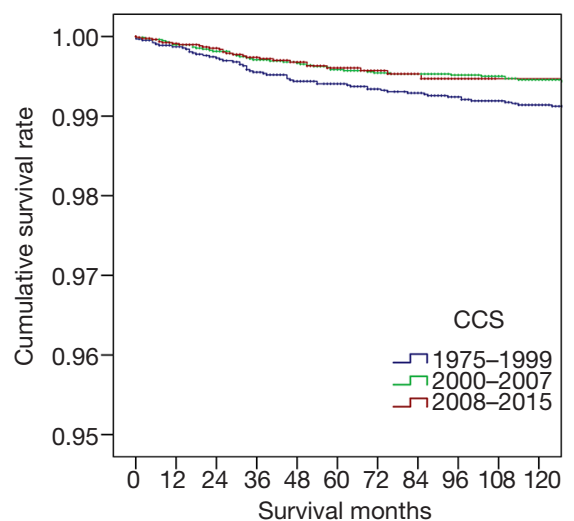

B

\begin{tabular}{cccccc}
\hline & $\mathrm{n}$ & $5-\mathrm{yr}$ CCS & 10-yrs CCS & $1975-1999$ & $2000-2007$ \\
\hline $1975-1999$ & 6303 & $98.30 \%$ & $96.10 \%$ & - & - \\
$2000-2007$ & 7619 & $98.60 \%$ & $96.70 \%$ & 0.087 & - \\
$2008-2015$ & 8054 & $98.70 \%$ & - & 0.081 & 0.971
\end{tabular}

C

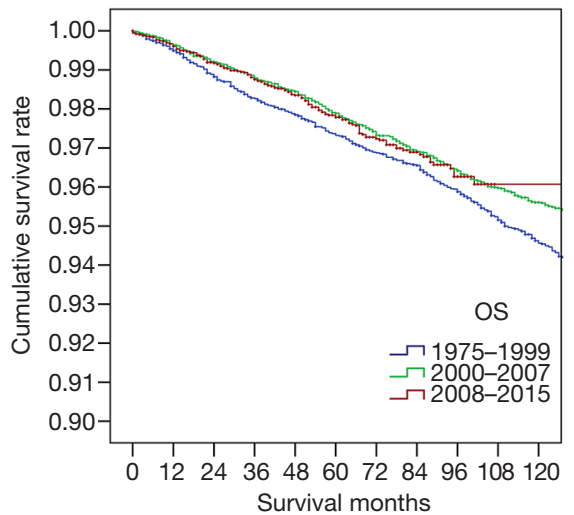

D

\begin{tabular}{cccccc}
\hline & $\mathrm{n}$ & $5-\mathrm{yr}$ OS & $10-\mathrm{yrs}$ CCS & $1975-1999$ & $2000-2007$ \\
\hline $1975-1999$ & 6303 & $97.30 \%$ & $94.60 \%$ & - & - \\
$2000-2007$ & 7619 & $97.90 \%$ & $95.60 \%$ & 0.010 & - \\
$2008-2015$ & 8054 & $97.80 \%$ & - & 0.097 & 0.778 \\
\hline
\end{tabular}

Figure 1 Survival analysis of stage I seminoma according to time period. Survival curves show the cancer-specific survival (CSS) and overall survival (OS) of patients with stage I seminoma in 1975-1999, 2000-2007, and 2008-2015 (A,B). The 5- and 10-year survival rates were listed and compared among the three time periods $(\mathrm{C}, \mathrm{D})$.

\section{Results}

After applying the exclusion criteria, a total of 21,976 men were analyzed. Patient characteristics are shown in Table 1. Mean age was 37.6 (SD 10.5) years and the median followup period was 12.8 years. The rate of radiotherapy among the patient cohort was $52.9 \%(11,622 / 21,976)$. OS was $91.7 \%$, and cancer-specific death was $1.0 \%$.

Between 1975 and 2015, 52.9\% of patients with stage I testicular seminoma received radiotherapy $(11,622 / 21,976$ cases). However, compared to 1975 , the proportion of patients who received radiation therapy in 2015 was lower (Figure 2). The overall rate of radiotherapy in $20^{\text {th }}$ century years was above $70 \%$, and in $1975,100 \%$ of registered patients (20/20 patients) received radiotherapy. After 2000, however, the rate of radiotherapy treatments gradually decreased to $46.7 \%$ (189/405 cases) in 2008, $18.6 \%$ (70/376 cases) in 2012 and 5.3\% (19/359 cases) in 2015.

Although the rate of radiotherapy has decreased, the rates of surveillance and chemotherapy have gradually increased. Before 2000, the proportion of patients receiving surveillance was maintained at about one fifth. However, after 2000, this value gradually increased, reaching a rate of up to $77 \%$ in 2015 . The proportion of patients undergoing chemotherapy remained at $6 \%$ or below before 2007 , but in 2008 , the number suddenly increased, remaining at between $17 \%$ and $20 \%$ from 2009 to 2015 . Our results showed that after 2008, more patients chose surveillance over radiotherapy, and that more patients preferred chemotherapy over radiotherapy after 2012. In other words, the rate of radiation was surpassed by surveillance in 2008 and by chemotherapy in 2012 .

In order to determine the patient characteristics related to the decline in radiotherapy rate, we stratified patients by age, race, marital status, or region, and plotted the rate of radiotherapy as a function of year. However, we observed no significant differences between the groups (Figure S1). We then aimed to analyze differences between patients receiving radiotherapy in the $20^{\text {th }}$ century with those in the $21^{\text {st }}$ century (Figure 3). Our results revealed differences in terms of age, marital status, and region between patients receiving radiation therapy in the $20^{\text {th }}$ and those in the $21^{\text {st }}$ century. In the $21^{\text {st }}$ century, fewer patients under the age of 34 chose radiotherapy, the proportion of married patients was smaller, and patients from the Northern plains and the Southwest were more likely to avoid radiotherapy.

To analyze the effect of changes in treatment regimens on patient outcomes, we analyzed the OS and CSS of patients with stage I seminoma (Figure 1). Results showed no significant differences in CSS. However, the OS was significantly reduced in patients in the 2000-2007 compared to the 1975-1999 time period. Despite this, the 
Table 1 Patient characteristics of SEER cohort diagnosed with localized testis seminoma from 1975-2015

\begin{tabular}{|c|c|}
\hline Groups & No. (\%) \\
\hline All & $21,976(100.0)$ \\
\hline \multicolumn{2}{|l|}{ Age groups, y } \\
\hline $5-14$ & $12(0.1)$ \\
\hline $15-69$ & 21,749 (99.0) \\
\hline $70+$ & $215(1.0)$ \\
\hline \multicolumn{2}{|l|}{ Race } \\
\hline White & 20,075 (91.3) \\
\hline Black & $536(2.4)$ \\
\hline Other & $1,365(6.2)$ \\
\hline \multicolumn{2}{|l|}{ Marital status } \\
\hline Single (never married) & $7,252(33.0)$ \\
\hline Married & $12,243(55.7)$ \\
\hline Others & $2,481(11.3)$ \\
\hline \multicolumn{2}{|l|}{ Laterality } \\
\hline Right & $11,705(53.3)$ \\
\hline Left & $10,235(46.6)$ \\
\hline Others & $36(0.2)$ \\
\hline \multicolumn{2}{|l|}{ Year of diagnosis } \\
\hline $1975-1985$ & $1,429(6.5)$ \\
\hline $1986-1997$ & $3,096(14.1)$ \\
\hline 1996-2005 & $7,543(34.3)$ \\
\hline 2006-2015 & $9,908(45.1)$ \\
\hline \multicolumn{2}{|l|}{ Region } \\
\hline East & $6,170(28.1)$ \\
\hline Northern Plains & $2,782(12.7)$ \\
\hline Pacific Coast & $11,247(51.2)$ \\
\hline Southwest & $1,743(7.9)$ \\
\hline Alaska & $34(0.2)$ \\
\hline \multicolumn{2}{|l|}{ Treatment } \\
\hline Radiotherapy & $11,622(52.9)$ \\
\hline Chemotherapy & $1,869(8.5)$ \\
\hline Surgery & $21,871(99.5)$ \\
\hline \multicolumn{2}{|l|}{ Status } \\
\hline Alive & $20,143(91.7)$ \\
\hline Dead (testis) & $220(1.0)$ \\
\hline
\end{tabular}

SEER, Surveillance, Epidemiology and End Results.
OS in $2008-2015$ was not statistically different from that of $1975-1999$.

\section{Discussion}

The proportion of stage I seminoma patients receiving radiation therapy decreased from $100 \%$ in 1975 to $5.3 \%$ in 2015. The rate of radiotherapy for the treatment of patients with stage I seminoma was surpassed by that of surveillance in 2008 and by that of chemotherapy in 2012. Patients aged under 34 years and married patients were more likely to avoid radiotherapy in the $21^{\text {st }}$ century.

Although similar observations were reported years ago, such results were no longer representative of the current situation. The present data about the proportion of patients who are refusing radiotherapy and instead choosing adjuvant chemotherapy or surveillance remains unclear. Thong et al. also reported a significant reduction in adjuvant radiotherapy, with only $37.7 \%$ of stage I seminoma patients receiving adjuvant radiotherapy in 2009 (3). Kamran et al. reported treatment trends for clinical stage I seminoma and found that the rate of radiotherapy in 2012 was nearly $18 \%$, whereas that of surveillance was $55.7 \%$ (39/70) (14). Our study also revealed a substantial change in the role of radiotherapy for the treatment of seminoma, which decreased to a rate of $5.3 \%$ in 2015 . Surveillance, rather than chemotherapy, was the main cause of such a decrease, with rates of $77.5 \%$ and $17.5 \%$ in 2015 , respectively. These results suggest that based on the highly curable nature of stage I seminoma, neither radiation nor chemotherapy is an acceptable strategy for the treatment of this disease. The main concerns regarding such therapies were delayed risks, such as secondary malignancies. To avoid such a risk, and even with a risk of recurrence of $15 \%$, treatment choices became increasingly directed towards surveillance $(15,16)$.

Our findings suggest that the value of radiotherapy in seminomas is correctly understood and properly evaluated. Woldu et al. analyzed stage I seminoma treatment patterns, stratified by hospital volume, and found that between 2004-2014, the rate of radiotherapy decreased from $32.4 \%$ in hospitals with low case volumes to $23.5 \%$ in hospitals with high case volumes (17). A survey in west China showed that $15.5 \%(16 / 103)$ of patients with stage I seminoma received adjuvant radiotherapy between 2008 and 2018 (18). These results indicated a difference in familiarity with radiotherapy regimens between facilities with different case volumes. Based on such results, textbooks on radiation oncology and rotation plans in 


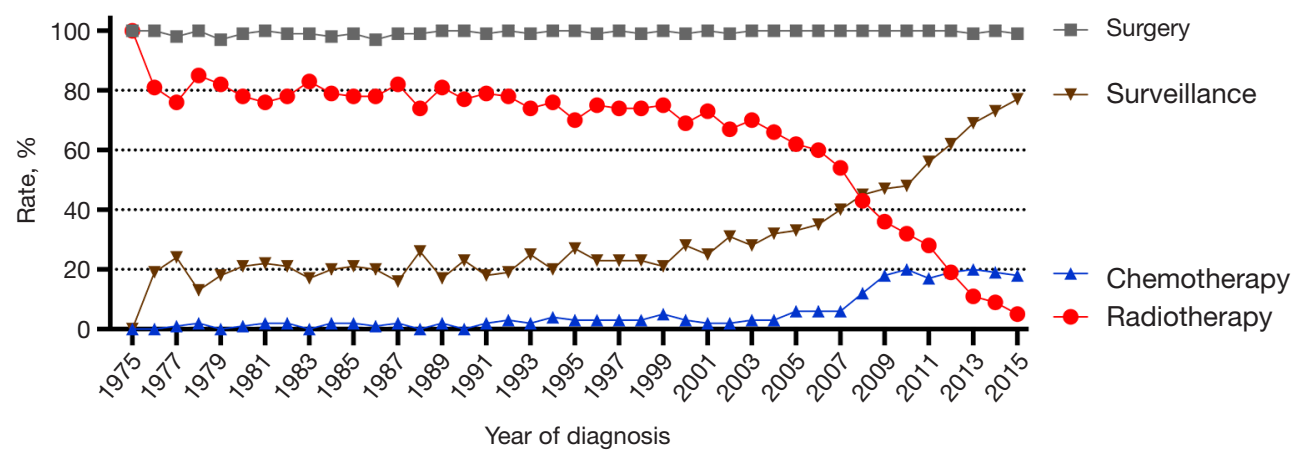

Figure 2 Trends in treatments for stage I seminoma between 1975 and 2015. Lines indicate trends in the proportion of patients receiving surgery (gray), radiotherapy (red), chemotherapy (blue) and surveillance (brown). Although the proportion of patients receiving surgery remains steady, radiotherapy shows a downward trend and chemotherapy and surveillance show a predominantly upward trend.

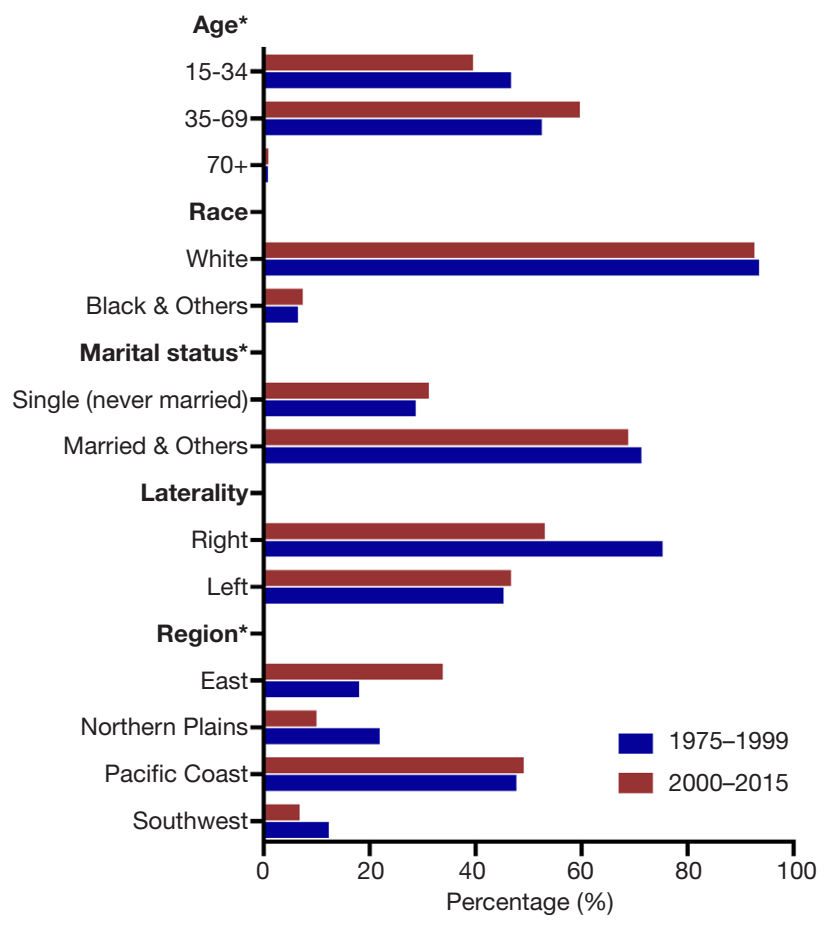

Figure 3 Characteristics of stage I seminoma patients who received radiotherapy in the $20^{\text {th }}$ or $21^{\text {st }}$ century. The percentage of patients with a certain age, marital status, and region (marked with *) were significantly different between 1975-1999 and 2000-2015.

training systems should be updated in order to guide the next generation of radiation oncologists. Further, through continued medical education, all radiation oncologists should update their knowledge of the use of radiotherapy for the treatment of seminoma, and thus, ensure a toxicityfree healthcare for this patient group (19,20).

Our study found the OS of patients with stage I seminoma was improved in 2000-2007 compare to that observed in 1975-1999. Where, although no differences in OS were observed between 2000-2007 and 2008-2015, the OS of patients with stage I seminoma in 2008-2015 was not significantly different from that observed in the previous century. On one hand, the improved OS observed in 2000-2007 compared to the previous century could be due to differences in patient selection during that time period. On the other hand, it is important to note that research on adjuvant treatments are mainly noninferiority studies. However, in the real world, such noninferiorities could transform cumulatively to inferiority results (21). Our data cannot confirm whether the OS of stage I seminoma will drop to the level of the last century. Thus, larger prospective studies are needed to clarify such ambiguities.

This study has several limitations: (I) the sensitivity, specificity, and accuracy of treatment data in the SEER database were limited because of the integrity of the treatment fields and the biases for unmeasured reasons (22); (II) due to the good prognosis of stage I seminoma, the statistical power of the survival analysis was insufficient; (III) the multicenter retrospective study was lack of a pathological review; and (IV) the sequence and intent of these treatments cannot be identified.

\section{Conclusions}

The treatment model for patients with stage I testicular seminoma has undergone radical changes in the past 40 years. External radiotherapy is no longer the standard treatment strategy in the real-world management of patients with stage I testicular seminoma. 


\section{Acknowledgments}

We would like to thank Editage Company for English language editing.

Funding: This research did not receive any specific grant from funding agencies in the public, commercial, or notfor-profit sectors.

\section{Footnote}

Reporting Checklist: The authors have completed the STROBE reporting checklist. Available at http://dx.doi. org/10.21037/tcr-20-2545

Conflicts of Interest: Both authors have completed the ICMJE uniform disclosure form (available at http://dx.doi. org/10.21037/tcr-20-2545). The authors have no conflicts of interest to declare.

Ethical Statement: The authors are accountable for all aspects of the work in ensuring that questions related to the accuracy or integrity of any part of the work are appropriately investigated and resolved. The study was conducted in accordance with the Declaration of Helsinki (as revised in 2013). The study protocol was deemed to be exempt from institutional review board of our hospital due to its retrospective nature and the need for informed consent was waived.

Open Access Statement: This is an Open Access article distributed in accordance with the Creative Commons Attribution-NonCommercial-NoDerivs 4.0 International License (CC BY-NC-ND 4.0), which permits the noncommercial replication and distribution of the article with the strict proviso that no changes or edits are made and the original work is properly cited (including links to both the formal publication through the relevant DOI and the license). See: https://creativecommons.org/licenses/by-nc-nd/4.0/.

\section{References}

1. Ghazarian AA, Kelly SP, Altekruse SF, et al. Future of testicular germ cell tumor incidence in the United States: Forecast through 2026. Cancer 2017;123:2320-8.

2. Ghazarian AA, Trabert B, Devesa SS, et al. Recent trends in the incidence of testicular germ cell tumors in the United States. Andrology 2015;3:13-8.

3. Thong AE, Lichtensztajn DY, Almario L, et al. Stage I testicular seminoma: a SEER analysis of contemporary adjuvant radiotherapy trends. J Urol 2013;190:1240-4.

4. Hanna NH, Einhorn LH. Testicular cancer--discoveries and updates. N Engl J Med 2014;371:2005-16.

5. Toner GC. Testicular cancer: Optimal management of stage I seminoma in 2015. Nat Rev Urol 2015;12:249-51.

6. Fosså SD, Horwich A, Russell JM, et al. Optimal planning target volume for stage I testicular seminoma: A Medical Research Council randomized trial. Medical Research Council Testicular Tumor Working Group. J Clin Oncol 1999; 17:1146.

7. Jones WG, Fossa SD, Mead GM, et al. Randomized trial of 30 versus 20 Gy in the adjuvant treatment of stage I Testicular Seminoma: a report on Medical Research Council Trial TE18, European Organisation for the Research and Treatment of Cancer Trial 30942 (ISRCTN18525328). J Clin Oncol 2005;23:1200-8.

8. Oliver RT, Mason MD, Mead GM, et al. Radiotherapy versus single-dose carboplatin in adjuvant treatment of stage I seminoma: a randomised trial. Lancet 2005;366:293-300.

9. Choo R, Thomas G, Woo T, et al. Long-term outcome of postorchiectomy surveillance for Stage I testicular seminoma. Int J Radiat Oncol Biol Phys 2005;61:736-40.

10. Bilici A, Ozturk T, Turkmen E, et al. Treatment preferences in stage IA and IB testicular seminoma: multicenter study of Anatolian Society of Medical Oncology. World J Urol 2015;33:1613-22.

11. Escudero-Ávila R, Rodriguez-Castano JD, Osman I, et al. Active surveillance as a successful management strategy for patients with clinical stage I germ cell testicular cancer. Clin Transl Oncol 2019;21:796-804.

12. Wingate JT, Etzioni R, Macdonald DM, et al. Treatment Trends for Stage I Testicular Seminoma in an Equal-Access Medical System. Clin Genitourin Cancer 2016;14:438-43.

13. Beard CJ, Travis LB, Chen MH, et al. Outcomes in stage I testicular seminoma: a population-based study of 9193 patients. Cancer 2013;119:2771-7.

14. Kamran SC, Seisen T, Markt SC, et al. Contemporary Treatment Patterns and Outcomes for Clinical Stage IS Testicular Cancer. Eur Urol 2018;73:262-70.

15. Ruf CG, Borck S, Anheuser P, et al. Adjuvant carboplatin therapy in patients with clinical stage 1 testicular seminoma: is long-term morbidity increased? J Cancer Res Clin Oncol 2019;145:2335-42.

16. Zengerling F, Kunath F, Jensen K, et al. Prognostic factors for tumor recurrence in patients with clinical stage I seminoma undergoing surveillance-A systematic review. 
Urol Oncol 2018;36:448-58.

17. Woldu SL, Matulay JT, Clinton TN, et al. Impact of hospital case volume on testicular cancer outcomes and practice patterns. Urol Oncol 2018;36:14.e7-14.e15.

18. Chen Z, Qiu S, Cao D, et al. Clinical characteristics of testicular seminoma in individuals in West China: a 10year follow-up study. Cancer Manag Res 2019;11:7639-45.

19. Groot HJ, Lubberts S, de Wit R, et al. Risk of Solid Cancer After Treatment of Testicular Germ Cell Cancer in the Platinum Era. J Clin Oncol 2018;36:2504-13.

Cite this article as: Jia S, Qiu J. Decrease in radiation therapy rates in patients with stage I seminoma: a population-based study. Transl Cancer Res 2021;10(1):417-423. doi: 10.21037/tcr20-2545
20. Kier MG, Hansen MK, Lauritsen J, et al. Second Malignant Neoplasms and Cause of Death in Patients With Germ Cell Cancer: A Danish Nationwide Cohort Study. JAMA Oncol 2016;2:1624-7.

21. Chen MH, Ibrahim JG, Lam P, et al. Bayesian design of noninferiority trials for medical devices using historical data. Biometrics 2011;67:1163-70.

22. Noone AM, Lund JL, Mariotto A, et al. Comparison of SEER Treatment Data With Medicare Claims. Med Care 2016;54:e55-64. 
A

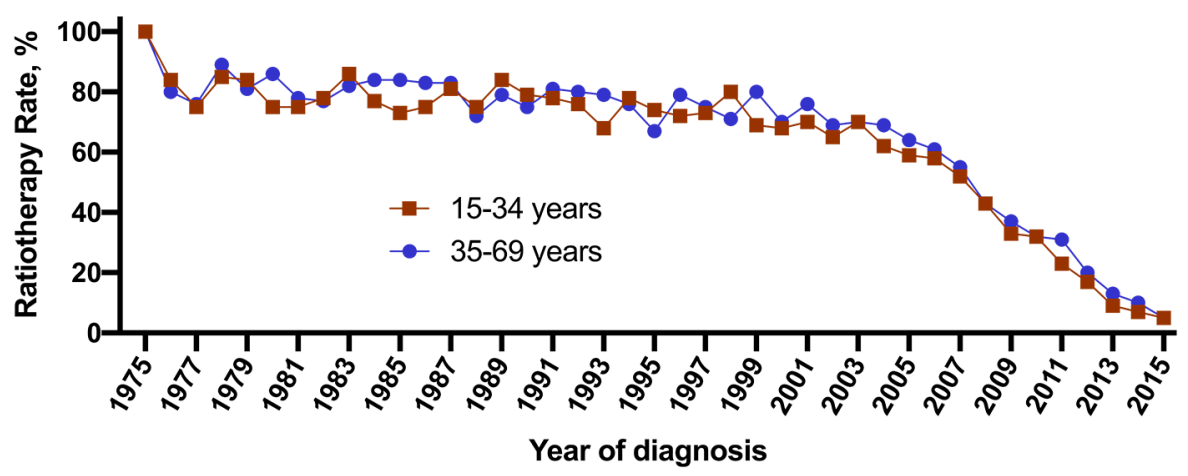

B

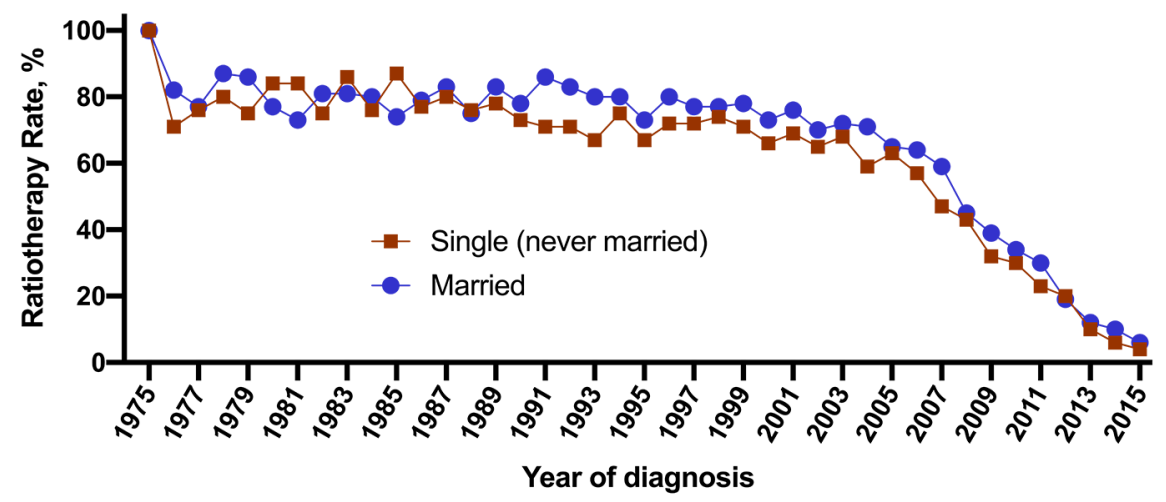

C
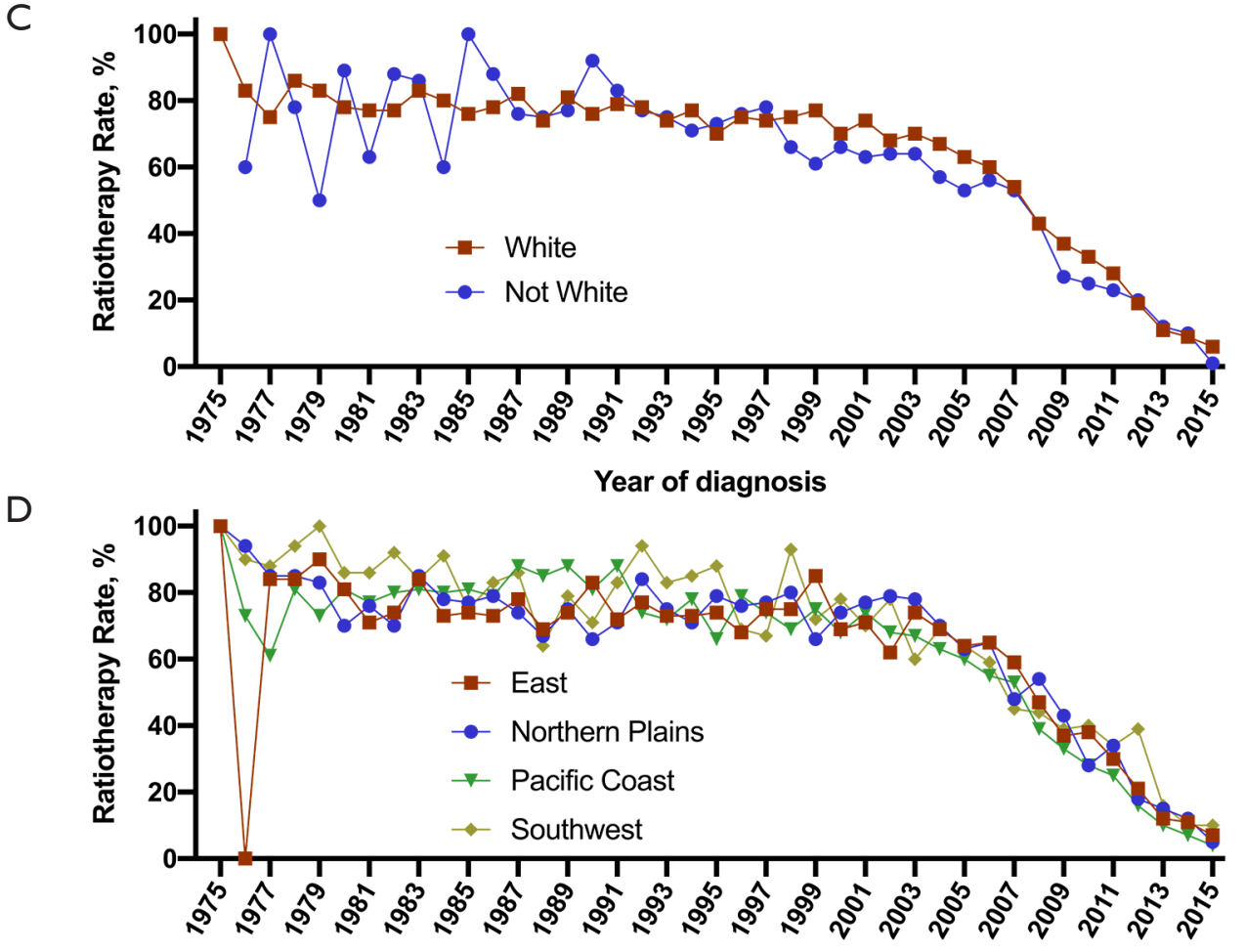

\section{Year of diagnosis}

Figure S1 Trends in treatments for stage I seminoma stratified by age, marital status, race or region. The lines show that the proportion of patients receiving radiotherapy declines between 1975 and 2015, but no significant differences were observed between the groups in terms of age, marital status, race or region. 